\title{
LOS POETAS YA NO CANTAN AHORA HABLAN \\ (Aproximaciones a la poesía de José Emilio Pacheco)
}

POR

SAMUEL GORDON

University of Pittsburgh

Al promediar la década de los sesentas, una nueva promoción de poetas despeinó a lectores y críticos conversando y tuteándolos desde la ventana abierta por una poesía que no parecía pura ni impura, política ni social, comprometida ni lírica. Tampoco intimista. Peor aún. Ni siquiera era inútil. Ya se había aceptado y comprendido su inutilidad. Entre quienes se asomaron por aquella ventana, buena parte de la crítica ha creído distinguir a Nicanor Parra y Jaime Sabines, a Roque Dalton y Enrique Lihn, a Ernesto Cardenal y Mario Benedetti, a Antonio Cisneros y Roberto Fernández Retamar, a Juan Gustavo Cobo Borda, a Juan Gelman y a José Emilio Pacheco. Estos poetas evitaban todo discurso grandilocuente, toda solemnidad, toda importancia. En un tono distinto que rozaba a veces el susurro, incorporaban una poesía narrativa que contaba historias futiles, detalles banales; que prefería el tono coloquial de lo cotidiano. Léase tono, no lenguaje. Aquí cabía la desesperanza y el descreimiento, el fin del siglo y el del milenio. El final de la modernidad. Todo junto.

Promoción y no generación porque, aún cronológicamente, se trata de un fenómeno supra-generacional. Más que insurgir o ignorar, estos poetas dejaron de lado la experimentación y el hermetismo que habían caracterizado a la vanguardia. Acaso el hartazgo de la pura experimentación los trajo de regreso a la expresión diáfana, a la sencillez aparente. Hartazgo, no rechazo.

A pesar de la indeterminación y dudosa efectividad del criterio generacional, la agrupación de escritores por generaciones ha seguido en México una inexplicada periodización por décadas y se ha aplicado con mayor frecuencia y especificidad a los poetas. Aunque ni científica ni acertada - y hasta innecesaria si se considera que la crítica parece interesarse menos en los autores que en los textos o los lectores - la creciente falta de funcionalidad de la teoría generacionista no parece haber afectado mayormente su uso continuo. Por el contrario, la comodidad ha seguido reuniendo a los nacidos en determinada década o a quienes publicaron su obra temprana entre tales o cuales años, repartiendo elementos comunes a aquellos 
que, la mayòría de las veces, poco tienen en común excepto la insistencia ajena en fijar cronogramas y delimitar parcelamientos. Esta comodidad crítica ha ayudado a envasar y rotular las grandes cantidades de materia prima que consumen con mayor frecuencia los historiógrafos panorámicos: nombres y fechas.

Para no quebrantar irreverentemente esta inútil tradición, consignemos que el autor que aquí interesa, José Emilio Pacheco, nació en la ciudad de México el 30 de junio de 1939, lo que ha permitido a la crítica situarlo junto a los poetas nacidos entre 1931 y 1940. Entre los más recordados: ThelmaNava (1931), Marco Antonio Montes de Oca (1932), Juan Bañuelos (1932), Isabel Fraire (1934), Gabriel Zaid (1934), Sergio Mondragón (1935), José Carlos Becerra (1937-1970), Jaime Augusto Shelley (1937), Eraclio Zepeda (1937), Francisco Cervantes (1938), Oscar Oliva (1938), Jaime Labastida (1939) y Homero Aridjis (1940).

Hombre de letras en amplitud, José Emilio Pacheco ha practicado con asiduidad poesía, cuento, novela, crítica, ensayo, crónica literaria, drama, guión cinematográfico, trađucción, versiones y adaptaciones de todo tipo. Múltiple prodigación que seguramente contribuyó a la naturalidad con que transita de un género a otro o conjunta enfoques, temas, técnicas y tratamientos, a veces, dentro de las presuntas paredes unitarias que todavía se concede al libro. No parece inquietarle la incomodidad de la genología ante la hibridación a que somete a los géneros. Algunas de sus preocupaciones tópicas, como la destrucciốn y el desgaste, la pérdida irremediable, el inexorable transcurrir del tiempo, la experiencia cotidiana ${ }^{1}$, mantienen una notable coherencia temática y parecen acercarlo a muchos poetas practicantes de la discutida poesía conversacional, para unos. Para otros, dialogal, coloquial, existencial, antipoesía y como quiera denominársele. Lectores y críticos no se reponen aún de la sobriedad y calidad inocultables de sus primeros libros de poesía: Los elementos de la noche (1963) y El reposo del fuego (1966), escritos entre los dieciocho y los veinticinco años de edad. Lejos de toda inmadurez, era difícil encontrar en ellos alguna falla mayúscula insoslayable. Meditados y cuidados, revelaban un oficio infrecuente en un poeta tan joven.

Revisemos la recepción temprana de dos de sus más inteligentes y agudos compañeros:

\footnotetext{
${ }^{1}$ Así lo advirtió tempranamente Carlos Monsiváis en La poesía mexicana del siglo $X X$. (Antología). (México: Empresas Editoriales, 1966) 70-71. También destacan algunos de estos elementos Julio Ortega en "Poemas de José Emilio Pacheco" en la compilación de Hugo J. Verani, José Emilio Pacheco ante la crítica (México: Universidad Autónoma Metropolitana, 1987) pp. 101 y ss. y José Miguel Oviedo en el trabajo que prologó su selección antológica "José Emilio Pacheco: la poesía como Ready Made" recogido también en la compilación de Verani 23.
} 
Los elementos de la noche,.. es una obra coherente, cuya característica primordial es el rigor. Estos poemas son hechos únicos, inmanentes, creaciones cuyo centro de gravedad no es la actitud política del autor, ni sus pasiones muy personales, ni su urgencia de confesión, sino el libre amor a la poesía. Y esta comunión, por su misma y perfecta intensidad, da lugar al mundo que precisa: la palabra que edifica, servida por la inteligencia y la vocación, un orbe que le pertenece y en donde sólo ella $-\mathrm{y}$ no sus equivalentes políticos o autobiográficos-podrá habitar. Aquí la poesía sirve como visión última de las cosas, la aliada del páramo de fuego. En las ruinas, en la melancolía, la oscuridad deja de ser el más fiel elemento de la noche. No hay pesimismo, sino una irremediable sensación de pérdida. La poesía ha perdido a la realidad y siente la nostalgia de su poder, del tiempo cuando cada palabra era acto y modificación, cuando las imágenes transformaban al mundo. Los elementos de la noche es la elegía por todos los poderes irrecuperables, por la sensación hueca y angustiosa que produce ignorar el nuevo centro de las cosas .... José Emilio Pacheco no está exento del peligro de la retórica. No por la imposibilidad de elección ... o por la reiteración de procedimientos ..., sino por la perfección de su sistema verbal que puede, en un momento dado, desdeñar el talento para satisfacer el oficio. Con todo, la sabiduría literaria de Pacheco ..., su lealtad a la vocación y su autocrítica no permiten ni autorizan tales prevenciones ${ }^{3}$.

\section{Zaid se refirió a El reposo del fuego como:}

... un libro entero sin la palabra tú. Libro calcáreo, seco, desolado. Dividido en tres partes sin títulos, de quince poemas cada una: un sólo gran poema unitario. La misma exactitud formal en los poemas, casi todos breves, sin rima ni medida uniforme, y sin embargo desplegados con el rigor de un buen soneto. Todo lo cual puede señalarse, pero no está pidiendo ser visto. Por el contrario, el libro es de

\footnotetext{
${ }^{2}$ Son ilustrativos los desacuerdos terminológicos a pesar de las coincidencias. Durante un intercambio de ideas entre César Fernández Moreno y Roberto Fernández Retamar, Fernández Moreno planteó la pregunta acerca de "la poesía conversacional, o dialogal, o coloquial; o existencial, como algunas veces yo mismo la he llamado: o antipoesía, como varios otros la han designado y designan". A lo que Fernández Retamar puntualizó: "en cuanto al término conversacional, no sé cuándo habrá comenzado a emplearse por vez primera en nuestra lengua para aplicarlo a este tipo de poesía. Hablando el otro día, yo te decía que en un libro mío de hace ya veintidós años, Alabanzas, conversaciones (1955), aparece el tẹ́rmino". Consúltese Roberto Femández Retamar, Para una teoría de la literatura hispanoamericana (La Habana: Editorial Pueblo y Educación, 1984) 96-97. Esta entrevista no aparece en la primera edición (La Habana: Casa de las Américas, 1976) ni en la edición mexicana subsiguiente (México: Nuestro Tiempo, 1977).

${ }^{3}$ Monsiváis 70-71.
} 
una modestia engañosa. Parece deliberadamente rehuir toda frase o imagen memorable, con la excepción de un poema de tres líneas, que a pesar de su levedad se queda gravitando en la memoria:

\author{
El viento trae la lluvia. \\ En el jardín \\ las plantas se estremecen ${ }^{4}$.
}

... La perfección formal cumple así una función que de ninguna mạnera puede reducirse al ejercicio, el lucimiento o el servil cumplimiento de cánones tradicionales o arbitrarios. Su función es combativa, de lucha contra el desierto y contra el tiempo, y hasta cierto punto oblativa: de rendición anticipada. Esta lucha puede también cumplirse en el silencio, como sucede a veces en esos poetas mejores .... Es más bien el reverso del libro, su parte soterrada; es esa frescura que estamos esperando todos los que creemos en José Emilio Pacheco ${ }^{5}$.

Su obra poética puede dividirse en dos periodos. El temprano se consuma con las nombradas. El siguiente se inicia con No me preguntes cómo pasa el tiempo (1969), núcleo de nuestra curiosidad indagatoria. Libro a partir del cual la poesía de Pacheco es otra. No solamente la poesía, también sus libros. Postulamos y privilegiamos la versatilidad estructural de este libro, porque inauguró el funcionamiento de los sucesivos como revistas, con secciones fijas sobreentendidas para el autor y los lectores y consumidores habituales de su poesía ${ }^{6}$. Libro que parece haberse convertido en un molde de vaciado irrompible. Ganador del Premio

\footnotetext{
${ }^{4}$ Es pertinente traer a colación el comentario que sobre este poema confió Pacheco a uno de sus traductores al inglés: "En una conversación, Pacheco me explicó la función de este poema breve. Lo defendió como una pausa poética que deja respirar y una brisa que frena, por un instante, el fuego inextinguido. Considera al poema al mismo tiempo necesario e insatisfactorio; hacía falta una pausa, pero la pausa no resuelve la cuestión fundamental." Thomas Hoeksema, "Señal desde la hoguera: La poesía de José Emilio Pacheco" en Verani 82.

${ }^{5}$ Gabriel Zaid, Leer poesía (México: Joaquín Mortiz, 1972) 72-74.

- La poesía coleccionada después de No me preguntes cómo pasa el tiempo, excluyendo antologías y ediciones especiales o fuera de comercio, y obras que recogemos en otras partes del aparato crítico, incluye: Irás y no volverás (México: Fondo de Cultura Económica, 1973); Islas a la deriva (México: Siglo XXI Editores, 1976); Desde entonces (México: Ediciones Era, 1980); Tarde o temprano (México: Fondo de Cultura Económica, 1980); Los trabajos del mar (México: Ediciones Era, 1983; hay edición anterior homónima, reducida e inasequible, de la Universidad Autónoma de Nuevo León), Miro la tierra (México, : Ediciones Era, 1986) y Ciudad de la memoria (México: Ediciones Era, 1989).
} 
Nacional de Poesía en 1969, está dividido en cinco partes y un apéndice. Algunas de estas secciones devendrán libros en los que se reunirá buena parte de su producción poética posterior. Es desde la segunda persona implícita en el título de este libro, y el siguiente - de alguna manera complementario-, cuando se inicia un "tuteo" que lo acercaría a lo conversacional pero, al mismo tiempo, se establece una distancia mediatizada por los andamios cultos y políglotas que lo entrecruzan. Entre las "secciones permanentes" aparece la animalia que conforma breves bestiarios o fábulas enternecedoras y estremecedoras que apuntan siempre hacia el hombre como bestia mayor. Esta sección - siguiendo la costumbre de Pachecoproclamó recientemente su independencia libresca. En octubre de 1985 un grupo editorial jaliscience reunió bajo el título de uno, cincuenta de estos poemas divididos en tres ámbitos: "de agua", "de aire" y "de tierra", conformando un variado Album de zoología?.

Aunque proyectada desde antes, se configura aquí otra sección permanente a partir de las versiones y transferencias intertextuales que Pacheco se ha negado a considerar como traducciones:

Las 'aproximaciones' con que terminan todos mis títulos .. se juntan en un capítulo final que suma algunas nọ recogidas previamente. Como la refundición de lo ya publicado, la práctica de traducir poesía sólo admite dos posiciones discordantes. No tengo nada contra los traductores académicos pero mi intención es muy distinta: producir textos que puedan ser leídos y juzgados como poemas en castellano, reflejos y aún comentarios en torno de sus intactos, inmejorables originales. A menudo se trata de 'imitaciones' que ..., sólo comparten el tema con la página que les dió nacimiento ${ }^{8}$.

No me preguntes como pasa el tiempo incluye catorce poemas "aproximados". Recuerda Pacheco que estas versiones empezaron como ejercicios en los cursos de lenguas clásicas y modernas. En algunas ha intentado traducir - "aproximarse" a- textos no vertidos al español con anterioridad. Otras se apoyan en diversos traductores?. Insiste en aclarar que no son, como podría creerse, "traducciones de

\footnotetext{
${ }^{7}$ José Emilio Pacheco, Album de zoología (Guadalajara: Cuarto Menguante Editores, 1985) 86pp. Este libro compiló Animalia procedente de No me preguntes como pasa el tiempo, Irás y no volverás, Islas a la deriva, Desde entonces y Los trabajos del mar.

${ }^{8}$ José Emilio Pacheco, Tarde o temprano (México: Fondo de Cultura Económica, 1980) 10.

${ }^{9}$ Entre los traductores acreditados se cuentan: Angel María Garibay, Miguel León Portilla, Marcela de Juan, Robert Graves, Omar Alí-Shah, Jaime García Terrés, Emilio García Gómez, Rex Warner, Ramón Xirau, Mónica von Hofmannsthal, Johanna Emmanuelli
} 
traducciones" sino "poemas escritos a partir de otros poemas". Considera que no debiera firmar estos trabajos, que son "una obra colectiva que debiera ser anónima"10. En un texto ligeramente anterior, Pacheco aplicaba y validaba esta óptica en las primeras traducciones de Salvador Novo:

\begin{abstract}
"Lo que Novo, adolescente de dieciocho años, aprende en·De la Selva es la posibilidad de expropiar, para los fines de su propia lengua y dentro de su molde, la dicción poética angloamericana, como los modernistas habían ampliado inconmensurablemente el repertorio lírico castellano con recursos aprendidos en Francia"'11.
\end{abstract}

Cuando en 1984 aparecieron independizadas sus Aproximaciones ${ }^{12}$, en una aguda reseña preguntaba Marco Antonio Campos cómo nacieron y se dieron estas versiones. Supone, atinadamente, que algunas fueron ejecutadas por encargo, otras por disciplina y algunas más por lectura, por puro placer. A veces fue por ad̉miración a un poeta, pero también la coincidencia de temas y preocupaciones o, por requerimientos del trabajo periodístico en ocasión de un aniversario luctuoso, por amistad, o por mero agradecimiento ${ }^{13}$.

No me preguntes cómo pasa el tiempo sirve también de escenario para el debut de dos heterónimos en el apéndice denominado "Cancionero apócrifo" precedido por epígrafes de dos poetas que de manera notoria utilizaron heterónimos: Antonio Machado y Fernando Pessoa. A la manera pessoana, se les provee de datos biográficos coherentes, contextualizados y verosimiles. Se trata de Julián Hernández (1893-1955) y deFernando Tejada (1932-1959), quienes reaparecerán en páginas posteriores de $\mathrm{Pacheco}^{14}$.

Huertas, Salvador Barros, Emilio Carballido, Henrique González Casanova, Peter Avery, John Heath-Stubbs, Peter Beilenson, Kenneth Rexroth, Ikuko Atsumi y John Bierhorst. 10. Pacheco, Tarde o temprano 10.

"José Emilio Pacheco, "Nota sobre la otra vanguardia" Revista Iberoamericana XLV. 106107 (1979): 328. Mantiene iguales conceptos y terminología en un texto posterior: "Así pues, para el Rubai'yat he expropiado la más reciente traducción británica... Aproximaciones 7.

${ }_{12}$ José Emilio Pacheco, Aproximaciones (México: Editorial Penélope, 1984) 189 pp.

${ }^{13}$ Marco Antonio Campos, "Aproximaciones de José Emilio Pacheco", Vuelta Abril 1985: 43-44.

${ }^{14}$ Algunos comentarios sobre la vida y obra de su heterónimo Julián Hernández parecen inexcusables. Hijo de padre español y madre norteamericana, dos nacionalidades tan enraizadas y conflictivas en la identidad mexicana, la producción bibliográfica que le atribuye Pacheco alude, revelando contradicciones y ajustes de cuentas, a algunos asuntos clave muy discutidos y discutibles de la historia política de México. La tan nombrada 
Algunos textos de este libro apuntan a redelinear ciertas poéticas. En "Crítica a la poesía" se insinúa un posible punto de partida: "Quizá no es tiempo ahora, nuestra época nos dejó hablando solos". Páginas adelante, en "Disertación sobre la consonancia", aparecen indicios de ruptura con su poesia anterior $\mathrm{y}$, también, se da por supuesto el previsible desacomodo del lector frente a las nuevas propuestas: "debe plantearse ... una redefinición que amplíe los límites (si aún existen límites) .... Una palabra, pocas sílabas, un nombre ... que evite las sorpresas y cóleras de quienes - tan razonablemente - ante un poema dicen: "esto ya no es poesía"."

Desde la conciencia de su auto-referencialidad, este texto poemático replantea, casi defensivamente, la interrogante acerca de las condiciones en que puede operar y ser reconocido como poesía. Cuestión pertinente porque, por lo general, es la confrontación del texto con las tradiciones literarias la que suele determinar y responder a esta pregunta. En otras palabras, el enfrentamiento con los cánones poético y crítico - ambos deben contemplarse aquí desde el lector- establece el grado de inteligibilidad y los alcances de cada texto literario en cada lectura diacrónica. Ello decide sus posibilidades operativas, su vigencia, su eventual postergación, rechazo o resurrección ${ }^{15}$.

Pacheco parece concebir el intertex to poemático-léase su texto-como un acto estético que selecciona o rescata otro texto. Puede tratarse de un texto propio que se corrige o modifica, o puede ser un texto ajeno - con una "ajenidad" relativa, puesto que siempre puede "expropiarse"-, que se traduce, glosa, parafrasea, enmienda, altera o interpreta. El texto "original", incorporado y neutralizado por la tradición, la visión cotidiana o el simple desconocimiento es sometido a una inesperada e insólita apropiación que lo pasea por lugares compartidos con el lenguaje cotidiano o bien, por las esquinas más visibles de la publicidad o por los barrios donde pervive la cultura popular o por los salones de una aristocracia intelectual culta y políglota y se entrega al lector un nuevo texto resultante, entre renovado e irreconocible.

Esta descolocación del objeto literario o real fuera del contexto habitual contribuyó a recargar poéticamente algunos intertextos de No me preguntes cómo

Legítima defensa rectuerda, por su título y escaso tiro, con humor y de sosiayo, un folleto poco conocido que publicó la Asociación de Escritores de México a raíz de un conflicto gremial que mantuvo por pago de derechos de autor en un litigio entre Gabriel Zaid y el periódico Excélsior.

${ }^{15}$ Sobre estas interrogantes ha esclarecido puntos con remarcable lucidez Federico Schopf en su prólogo a Nicanor Parra, Poemas y antipoemas (Santiago de Chile: Editorial Nascimento, 1972) particularmente las páginäs 7-8. También el mencionado trabajo de Oviedo reflexiona sobre estos puntos. 
pasa el tiempo pero, la relectura de libros posteriores acusa una indiferenciación entre recurso y función. La repetición de recursos no asegura per se una reiteración de sorpresas estéticas. De otra manera: la reiteración de procedimientos en el cumplimiento de funciones ya desempeñadas, no confiere iguales posibilidades operativas a textos diferentes: La alternancia o superposición de textos y contextos y los diferentes niveles de intertextualidad que, con analogías y diferencias, han recibido nomenclaturas distintas ${ }^{16}$, merecen cierta reflexión adicional, por cuanto se distinguen de las voces que para Eliot interactúan en la poesía ${ }^{17}$, y que también utiliza Pacheco.

En su carta-poema a George Moore, Pacheco aseguraba que nada tenía que añadir a sus poemas y tampoco le interesaba comentarlos. Para él, la escritura poética constituye un lugar de encuentro con la experiencia ajena. Al escribir, el poeta despliega la mitad de un poema, la otra mitad la aportan el lector y su lectura. "No leemos a otros: nos leemos en ellos". Para Pacheco la poesía es un pacto secreto entre dos personas, casi siempre desconocidas, en el que cada lector se convierte en autor al reinventar los poemas mediante su lectura. En esto, parece seguir a buena parte de la crítica literaria en nuestro siglo que, como lo sugerimos

${ }^{16}$ Denominados "ready mades", "objets trouvés" y "collages" por la crítica para referirse a experimentalismos de dadaístas, surrealistas y cubistas; ante la ausencia de parámetros críticos que dieran cuenta de las nuevas posiciones del poeta frente al lenguaje en la poesía conversacional, se ha echado mano también de términos como "pastiche", "pop", "beat" etc.; para referirse a distintos aspectos de esta poesía que "ya no es poesía" y en la que el sujeto poético parece haberse convertido en un operador y distribuidor de niveles y situaciones de lenguaje, estableciendo nuevas relaciones con el texto y con el lector. Ubicados como digresiones al pie, sugerimos consultar los comentarios de Lilvia Soto en "Realidad de papel: máscaras y voces en la poesía de José Emilio Pacheco" en Verani pp. 109-121. Optamos por clarificar una separación más definida entre intertex to y voz por cuanto se hallan en niveles diferentes, aunque coactúen. Para ello, nos valdremos de la nota siguiente.

17 En una conocida conferencia, Eliot precisaba las voces poéticas y sus niveles de interacción. Después de descartar una única voz del poeta que habla a una sola persona pasa. a explicar "lo que para mí significan las tres voces: la primera es la voz del poeta hablando a sí mismo o a nadie. Mediante la segunda voz el poeta se dirige al público. La tercera, es la voz empleada para crear un personaje dramático hablando en verso, cuando lo que expresa, no lo diría como persona, sino sólo dentro de los límites de un personaje imaginario dirigiéndose a otro personaje imaginario. La distinción entre primera y segunda voz, entre el poeta que se dirige a sí mismo y cuando se dirige a otras personas ... señala la diferencia entre verso dramático, cuasi dramático y no dramático". T. S. Eliot, "The Three Voices of Poetry, The Eleventh Annual Lecture of the National BookLeague, Central Hall, Westminster, on Thursday 19th. November 1953. (London: Cambridge University Press, 1953) 4. 
al principio, ha ido desplazando el centro de gravedad del interés literario del autor al texto y de éste al lector ${ }^{18}$. Pero, a su vez, el autor se transforma en un relector perenne de su propio trabajo. Asi parece aseverarlo Pacheco con su actitud ante lo que escribe, re-escribe, glosa, traduce, aproxima, intertextualiza y recontextualiza: "respecto a lo que escribimos pueden tomarse dos actitudes y no existe un terreno de conciliación entre ambas: se cree que cada página es sagrada y no debe alterarse jamás; o bien se piensa en la poesía no como creación eterna sino como trabajo humano, producto histórico y perecedero: por tanto susceptible de mejorarse. No acepto la idea de 'texto definitivo'. Mientras viva seguiré corrigiéndome"19, y asi lo reafirma desde su poema "Manifiesto":

\author{
Todos somos poetas \\ de transición \\ La poesía jamás \\ se queda inmóvil
}

Y en el sexto poema de "Legítima defensa" denominado "Sabor de época":

$$
\begin{aligned}
& \text { Todo poema } \\
& \text { es un ser vivo: } \\
& \text { envejece. }
\end{aligned}
$$

"No hay relecturas. Al volver a un texto que nos sabemos casi de memoria ya no somos los mismos - sostiene Pacheco, ahora desde la posición del lector-, el mundo ha cambiado, la página surge por vez primera ante nuestros ojos"zo.

Su inscripción en lo conversacional -que, por cierto, denomina "realismo coloquial" - nos retrotrae a líneas confluyentes diversas. La vertiente más remota procedería de las primeras instauraciones de la dicción poética angloamericana. En sus reflexiones sobre "la otra vanguardia", a las que ya nos remitimos, cuajaban ideas prefiguradas en un texto más temprano, donde sostenía que $E l$ soldado desconocido del nicaragüense Salomón de la Selva y Espejo del mexicano Salvador Novo, constituian los antecedentes del "poema hablado"z. La vertiente más inmediata proviene de los poetas mexicanos nacidos en la década anterior:

\footnotetext{
${ }^{18}$ En la nota introductoria a sus Aproximaciones escribe: "Un libro, pues, en que importan más los textos que los autores.", p. 8.

${ }^{19}$ Pacheco, Tarde o temprano 10.

${ }^{20}$ José Emilio Pacheco, "Nuevo recuento de poemas de Jaime Sabines", Vuelta Agosto 1977: 34 .

21 Pacheco, Ibid. 34.
} 
Jesús Arellano, Rubén Bonifaz Nuño, Rosario Castellanos, Dolores Castro, Manuel Durán, Jaime García Terrés, Enrique González Rojo, Miguel Guardia, Jorge Hernández Campos, Eduardo Lizalde, Jaime Sabines y Tomás Segovia. Fue desde la revista Metáfora (1955-1957), capitaneada por "Chucho" Arellano que el poema hablado comenzó por incorporar, y acabó por conquistar, el "habla común"22.

Entre los elementos que pueden señalarse en dirección a otros poetas conversacionales de la promoción sugerida al inicio, cabe recordar que el epígrafe introductorio a No me preguntes cómo pasa el tiempo corresponde a Ernesto Cardenal, a quien Pacheco alude reiteradamente (como en "Juego de espejos": "Catulo imita a Emesto Cardenal" o en "A las puertas del Metro": "Si lo viera Ernesto Cardenal le diría ...", etc.). En el primer prólogo de Islas a la deriva, hay una dedicatoria a Juan Gustavo Cobo Borda y, para cerrar los breves ejemplos, el segundo verso del cernudiano "Birds in the night": "y como en un poema de Cisneros". A veces sorprende la cercanía de coincidencias, como entre el título de Enrique Lihn Poemas de este tiempo y de otro y No me preguntes como pasa el tiempo, donde tanto Lihn como Pacheco acentúan la centralidad de la cuestión temporal.

Pero señalar estas direcciones que entrecruzan coincidencias entre Pacheco y otros poetas conversacionales no permite establecer grados de afinidad, más bien tangencial, más allá de los siguientes:

1) La despersonalización del hablante.

2) Los desdoblamientos - sincrónicos y diacrónicos — de la voz poética.

3) La traslación del binomio yo-tú a un sujeto poético colectivo.

4) El aprovechamiento de otros textos poéticos como generadores de renovada productividad $\mathrm{y}$,

5) La narratividad.

Antes bien; a diferencia de otros poetas conversacionales y en aparente contradicción con su visión del poema hablado y "a diferencia de 1962, hoy son las otras tentativas las que representan la marginalidad y la disidencia. Por virtud de su triunfo y aunque se nieguen a reconocerlo, los antiguos rebeldes constituyen ahora el nuevo Establishment. Pero siempre habrá mil caminos abiertos, mil rutas muy distintas de la nuestra"23; Pacheco sólo conserva el tono. El complejo sistema de préstamos que entrecruza epígrafes de la alta literatura - léase canónica-, con dedicatorias, textos convocados, versiones, intertextos y hasta notas al pie de

\footnotetext{
22 Pacheco, Ibid 35.

${ }^{23}$ Pacheco, Ibid. 34.
} 
algunos poemas; en distintos tonos y niveles de hablantes diversos, voces y heterónimos, quienes a su vez lo entremezclan con términos publicitarios, anglicismos, neologismos sutiles y locuciones extranjeras en casi todos los idiomas que utilizan el alfabeto latino, hacen de la suya, una poesía extremadamente culta y hasta cuasi políglota, cargada de nostalgias por el canon elevado del Establishment anterior. En otras palabras, Pacheco no opone a la literatura canonizada una nueva literatura sin prestigio aparente sino que suscribe de manera tributaria, y refuerza, las normas existentes. En ello reside el mayor distanciamiento visible con otros poetas conversacionales.

La crítica más reciente sobre su poesía comienza a revelar desazón y cansancio frente a la reiterativa y previsible técnica de armado de sus libros ${ }^{24}$. Muchos pensamos que la edición de Tarde o temprano (1980), que señalaba sin duda su consagración en el ámbito de la poesía mexicana, pondría fin a la etapa de los libros-revista, estructurados por secciones y mediante recolección iniciada con $N o$ me preguntes como pasa el tiempo, libro que propusimos como parteaguas del periodo anterior.

Siguiendo las preferencias de Pacheco, privilegiemos una vez más al lector. Justo es que si iniciamos nuestro atisbo con la recepción temprana de su obra primera, lo clausuremos con los ecos últimos de lecturas más recientes:

Pacheco debía estar buscando algo después de un libro tan contundente como Tarde o temprano. Esa búsqueda ha sido interrumpida con una vuelta a los hábitos conocidos .... Pero es como intentar desprenderse de los vicios cotidianos ... la palabra conjunto adquiere más sentido en Miro la tierra. Las cuatro partes son cuadernillos también. Comprobamos que se mantiene el orden tradicional (aquí las traducciones-aproximaciones van al final). La pregunta sería: ¿deseaba el poeta alterar sus propias costumbres?

La otra inquietud tiene que ver con los poemas mismos. Pacheco es un poeta que ha hablado de la cotidianidad y del presente a partir de analogías. La sección más importante de Miro la tierra adopta una calidad cívica, pero pierde por ello la posibilidad de apelar a la plurisignificación. Dicho de otro modo: en sus más famosos poemas en torno a conceptos como ciudad e historia, Pacheco empleaba una poética especulativa. Pero ante una tragedia nacional no cabe más que la constatación, y por eso encontramos apoyaturas de tipo patriótico, público, y pocas veces asoma el hada sorpresa .... El final del poema es una arenga que seguramente todo lector compartirá, pero pór razones más políticas que poéticas .... Miro la tierra responde, pues, las dos preguntas iniciales. Dificilísimo es

${ }^{24}$ Edgar O’ Hara, "Cuando tiembla la poesía", Utopías Marzo-Abril 1989: pp. 67-68. 
trabajar con la inmediatez desde una poética colectiva. Ya no es conveniente concebir el libro como una reunión de cuadernillos"25.

Desde un principio postulamos la versatilidad estructural de No me preguntes como pasa el tiempo. Es claro que debemos matizarlo. Tarde o temprano, el paso del tiempo puede llegar a convertirlo en un molde, más estructural que versátil.

${ }^{25}$ O'Hara pp. 67-68. 